\title{
Laminaria hyperborea photosynthesis-irradiance relationship measured by oxygen production and pulse-amplitude-modulated chlorophyll fluorometry
}

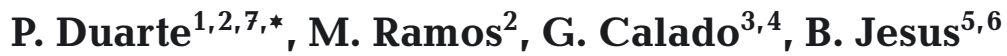 \\ ${ }^{1}$ CIAGEB, Global Change, Energy, Environment and Bioengineering R \& D Unit, Universidade Fernando Pessoa, \\ 4249-004 Porto, Portugal \\ ${ }^{2}$ CIIMAR, Interdisciplinary Centre for Marine and Environmental Research, 4050-123 Porto, Portugal \\ ${ }^{3}$ Universidade Lusófona de Humanidades e Tecnologias, 1749-024 Lisbon, Portugal \\ ${ }^{4}$ IMAR, Departamento de Ciências e Engenharia do Ambiente, Faculdade de Ciências e Tecnologia, \\ Universidade Nova de Lisboa, 2829-516 Caparica, Portugal \\ ${ }^{5}$ LUNAM Université, Université de Nantes, Mer Molécules Santé EA 2160, Faculté des Sciences et des Techniques, \\ 44322 Nantes cedex 3, France \\ ${ }^{6}$ Centro de Biodiversidade, Genómica Integrativa e Funcional (BioFIG), Faculdade de Ciências, Universidade de Lisboa, \\ 1749-016 Lisbon, Portugal \\ ${ }^{7}$ Present address: Norwegian Polar Institute, Fram Centre, 9296 Tromsø, Norway
}

\begin{abstract}
Information about photosynthesis-irradiance (P-I) relationships is crucial in many primary production studies. This is frequently obtained using incubation experiments, which may not simulate in situ conditions where algae are adjusting their photosynthetic systems to permanent light variations. There has been increasing interest in pulse-amplitude-modulated (PAM) chlorophyll fluorometry - which measures instantaneous photosynthetic response-particularly in the use of rapid light curves (RLCs) to minimize the confounding effects of light acclimation encountered with traditional 'steady-state' light curves (SSLC). However, there is still a lack of information about how oxygen SSLC curves and estimations from fluorescence P-I curves are related. The present study addresses some of these topics, using Laminaria hyperborea. The objectives of this study were to (1) determine the effect of light sequence (increasing or decreasing) in the estimation of P-I parameters, (2) characterize the daily patterns of P-I curve parameters, (3) compare oxygen and fluorescence P-I parameters and (4) evaluate the possibility of converting fluorescence P-I parameters into oxygen production measurements. Results showed that light sequence had no significant effect on P-I parameters (fluorescence and oxygen) and that P-I curves exhibited considerable differences over the day (F-ratio analysis). Fluorescence SSLCs and RLCs were good oxygen production predictors only at sub-saturating irradiances, when significant linear relationships were obtained with results from oxygen incubations. Thus care should be taken when interpreting PAM fluorescence gross production estimations from higher light intensities.
\end{abstract}

KEY WORDS: Photosynthesis-irradiance relationship - Oxygen incubations · Steady-state light curves $\cdot$ Rapid light curves

Resale or republication not permitted without written consent of the publisher

\section{INTRODUCTION}

A large number of authors have discussed the photosynthesis-irradiance (P-I) relationship in algae over the years (for a review see Duarte 2005). P-I curves are often defined using static parameters, e.g. initial slope and the maximum photosynthetic rate. However, P-I relationships are often dynamic, changing throughout the day as a result of endogeneous cycles, photoadaptation and photoacclimation pro- 
cesses. This dynamic nature may preclude the usage of static P-I relationships, i.e. equations with fixed parameters; instead, these 'parameters' may have to be treated as variables.

The P-I relationship of macroalgae is frequently studied using incubation experiments, where algae are kept under different light levels for a period long enough to observe significant changes in dissolved oxygen within the incubation vessels, as a result of photosynthesis and respiration. Physiologically 'oriented' experiments may use small pieces of macroalgae (e.g. Franklin \& Badger 2001), allowing more experimental control of light-intensity conditions and, possibly, reducing error variance among replicates if pieces of similar shape, size and cut from the same part of the thallus are used. These experiments provide useful physiological information due to high control of experimental conditions. However, if the main interest is simulating in situ photosynthesis, within the scope of an ecologically 'oriented' study, it is probably more appropriate to use whole organisms in experiments with proper replication, to account for the variability arising from intraspecific morphological and physiological differences and from variation in light exposure of different parts of the thallus during incubation experiments. It is likely that this increased variability may mask, to a certain degree, aspects that are revealed in physiologically oriented experiments. However, results may be useful in extrapolating to field conditions and in obtaining useful insights about in situ primary production.

Whatever approach is used in incubation experiments, there are several methodological problems related to feedbacks between experimental conditions and obtained physiological responses. Most of these feedbacks, limiting the accuracy of photosynthesis measurements, have been addressed previously, such as oxygen saturation, $\mathrm{pH}$ changes and nutrient depletion (e.g. Dromgoole 1978a,b, Littler 1979).

Under in situ conditions, algae are exposed to large variations in light as a result of a combination of sunlight and water turbidity variability associated with thallus movements caused by waves and currents. It has long been recognized that algae are capable of adjusting their photosynthetic apparatus to some of this variability over time scales that range from minutes to days or weeks (e.g. Davison 1991, Falkowski \& Raven 1997). Short-term adjustments to variations in ambient light may include changes in Photosystem II (PSII) cross-section and protective processes, such as non-photochemical quenching to limit photosystem damage under high light intensities (e.g. Falkowski \& Raven 1997). The term 'acclimation' or 'photoacclimation' is used by several authors to refer to long-term changes, such as changes in pigment and protein concentrations, over time scales of days or weeks (e.g. Falkowski \& Raven 1997).

During incubation experiments where algae are exposed for several minutes to the same light intensity, it is expected that organisms may adjust their photosynthetic apparatus; therefore, their photosynthetic response may change during the experiment. If the experiment realistically mimics in situ ambient light variability, the measured photosynthetic response will be ecologically relevant because it will integrate the photosynthetic activity over the experimental procedure time scale. However, the effects of light intensity and physiological adjustments are confounded because they are also integrated. Therefore, the data obtained will be of limited interest for predicting the photosynthetic response of the same algae under different light field conditions. Thus, an ideal method of measuring photosynthetic rates should allow almost instantaneous measurement. The usage of pulseamplitude-modulated (PAM) chlorophyll fluorometry of PSII has been proposed as a reliable alternative to classical incubation procedures (e.g. Ralph \& Gademann 2005). Rapid light curves (RLCs) obtained from PAM measurements are used to minimize the confounding effects of light acclimation encountered with 'steady-state' traditional light curves (SSLCs) (Serôdio et al. 2005). Moreover, the availability of submersible PAM instruments may eliminate sampling algae and transporting them to the laboratory with all associated experimental artifacts. However, some controversial results occur when P-I curves obtained from oxygen production incubation experiments are related to PAM-based estimates obtained under similar conditions e.g. with the macroalgae Porphyra columbina (Rhodophyta), Ulva australis (Chlorophyta) and Zonaria crenata (Phaeophyta) (Franklin \& Badger 2001); with the macroalgae U. rotundata, U. olivascens and P. leucosticta (Figueroa et al. 2003); with the benthic diatom Cylindrotheca closterium (Morris \& Kromkamp 2003); with phytoplankton (Goto et al. 2008, Hancke et al. 2008); with thin- and thick-leaved marine macroalgae (Nielsen \& Nielsen 2008); and with phytoplankton (Blache et al. 2011). The usefulness of chlorophyll fluorescence as a photosynthesis proxy depends on the existence of a predictable relationship with the quantum yield of oxygen or carbon dioxide evolution.

The current work was part of a larger study to estimate macroalgal primary production in different habitats along the Portuguese shore and over the Gorringe seamount. Considering the light intensity 
and temperature variability in these habitats, a macroalgal production model will be used to estimate primary production over time. For the purposes of model parameterization, it was necessary to have adequate information about the P-I parameters of the main algal species. However, parameter variability associated with the physiological status of algae and experimental artifacts may prevent accurate primary production estimation - the dynamic nature of $\mathrm{P}-\mathrm{I}$ parameters may pose serious challenges to current estimation methods. Therefore, the experiments in this study were designed to elucidate methodological details associated with the following questions:

(1) When performing a P-I experiment, does the direction of change of the light intensity sequence (increasing or decreasing) imposed upon the algae have a significant influence on the results?

(2) Considering diel rhythms in algal physiology, such as those involved in the xanthophyll cycle (Falkowski \& Raven 1997, Gévaert et al. 2003), do P-I curves obtained at different times of the day differ significantly?

(3) Are the answers to the previous questions similar independent of whether measurements are based on oxygen production from incubation experiments or on PAM fluorometry?

(4) Is there a simple way to convert PAM-derived photosynthetic parameters with those derived from oxygen production measurements?

It is important to mention some of the practical implications the answers to the above questions have when the overall goal is predicting in situ primary production. For example, if the answer to either the first or second question is positive, the design of the physiological experiments must take into account the implied variability, especially if results are to be extrapolated to field conditions.

\section{MATERIALS AND METHODS}

\section{Sampling sites}

Laminaria hyperborea individuals were collected at approx. $10 \mathrm{~m}$ depth from a sampling site on the northern coast of Portugal near the city of Vila do Conde (ca. $41^{\circ} 20^{\prime} 22^{\prime \prime} \mathrm{N}$ and $8^{\circ} 45^{\prime} 14^{\prime \prime} \mathrm{W}$ ) in April 2012. The algae were kept in water at $13^{\circ} \mathrm{C}$ and $37 \mathrm{psu}$, in a tank exposed to natural diffuse sunlight and were covered with a mesh to prevent very high light intensities. The experimental temperature $\left(13^{\circ} \mathrm{C}\right)$ and salinity (psu) were similar to the values in the sampling area.

\section{Oxygen P-I curves}

P-I experiments were carried out within 1 or $2 \mathrm{~d}$ after sampling by measuring oxygen fluxes inside sealed 12.5 l plexiglas incubation chambers at 7 different irradiance levels. These irradiance levels corresponded to spatially averaged values within the cameras, measured at several points to guarantee that they were representative of the irradiance received by the seaweeds during the incubations. In all experiments, oxygen was monitored in 4 incubation chambers: one as a control, containing only water, and 3 replicates with whole algal specimens cleaned from epiphytes. These specimens had a maximum length of ca. $0.5 \mathrm{~m}$. When fitted in the incubation chambers some could be partially folded due to their size. However, the incubator was completely white to ensure, as far as possible, homogeneous illumination, minimizing shaded areas. A fifth chamber was used for PAM fluorometry measurements with the Diving-PAM (Walz) (see following subsection). The chambers were partially submersed in a larger, thermostatically controlled 110 l PVC white cooling bath. Temperature was controlled with an error of $<1^{\circ} \mathrm{C}$. Water movement inside each incubation chamber was maintained with a submersible pump (1200 $\left.\mathrm{l} \mathrm{h}^{-1}\right)$, equipped with a diffuser to reduce turbulence. Oxygen concentrations were measured using luminescent dissolved oxygen probes connected to a data-logger (Hach ${ }^{\circledR}$ HQ40) that registered measurements every minute. Incubations were performed under 5 natural light fluorescent lamps (30 W fluorescent tubes, Osram ${ }^{\circledR}$ BIOLUX) that, combined with different mesh filters, provided 7 light levels of photosynthetically active radiation (PAR): 0, 24, 63, 107, 212, 551 and $931 \mu \mathrm{mol} \mathrm{m} \mathrm{m}^{-2} \mathrm{~s}^{-1}$. For each P-I incubation, the successive irradiance periods lasted ca. 30 min. Respiration rates were calculated during the dark incubation. The entire incubation set ran between 3 and $3.5 \mathrm{~h}$ for all experiments. Oxygen saturation levels ranged from 96 to $118 \%$ during all incubations.

Two experiments were performed. On the first day after sampling, a repeated-measures experiment was carried out with an increasing/decreasing irradiance gradient using the 7 light levels described above (hereafter referred to as Expt 1). Therefore, the same individuals were incubated under increasing and then decreasing light levels, and respiration rates were measured at the beginning of the increasing light shift and at the end of the decreasing light shift. On the second day, 3 incubations were carried out: in the morning, at midday and during the afternoon, 
with the same 7 increasing light levels (hereafter referred as Expt 2). During each of the 3 incubations, the same individuals were used at the various light levels, but individuals were exchanged between incubations. Both experiments were carried out at seawater temperatures of 13.5 to $14^{\circ} \mathrm{C}$. The option for a repeated-measures design was justified by the time necessary to initialize the experiments with new individuals and the effects that this may have had in keeping water temperature stable.

After incubations the volume of each kelp was measured by immersing the specimens in a graduated beaker. Subsequently, algae were dried to constant weight and their biomass was determined. Chamber volume was corrected for algal volume, and both respiration and photosynthetic rates were expressed as mg $\mathrm{O}_{2} \mathrm{~g}^{-1}$ algal dry weight (DW) $\mathrm{h}^{-1}$. Gross photosynthesis was calculated from net photosynthesis, obtained at each light level, and respiration in the dark.

\section{PAM RLCs and SSLCs}

PAM fluorescence was measured using the DivingPAM. During both experiments, RLCs were measured in one of the incubated specimens (see 'Oxygen P-I curves') prior to switching light to the next level. Therefore, before carrying out the RLCs, these specimens were adapted to each light level of the incubator for a period of between 20 and $30 \mathrm{~min}$. RLCs were constructed using the PAM halogen light source with $30 \mathrm{~s}$ light steps and set up to be similar to the light levels used in the oxygen incubations: $0,14,35,66$, $102,208,353,525$ and $950 \mu \mathrm{mol}$ photons $\mathrm{m}^{-2} \mathrm{~s}^{-1}$. These light levels were selected after calibrating the PAM quantum sensor against 2 different calibrated quantum sensors: a Delta OHM HD 9021 and a LiCOR Li-1400.

RLCs were measured at each incubation level on the alga's stipe and on the blade. A total of 26 RLCs was obtained during the first experiment (14 and 12 during the increasing and decreasing light phases, respectively), and 42 RLCs during the second experiment $(7$ for the blades and 7 for the stipes per incubation). All measurements were conducted using the universal sample holder Diving-USH (Walz), with an underwater clip for dark adaptation, to prevent the influence of external light. Each RLC started as soon as the sample holder was put in place. Therefore, algae were in darkness $<5 \mathrm{~s}$ before the first fluorescence measurement (during each RLC) took place, and it is assumed that obtained results reflect the
20 to 30 min acclimation (see 'Oxygen P-I curves') to each light level, mimicking an in situ situation in which a RLC is carried out on an alga with an ambient light history. Blade and stipe absorptance were measured using the Diving-USH and the DivingPAM PAR light sensor in opposition to the actinic light delivered by the PAM.

The RLCs described above are not directly comparable to the oxygen P-I curves for the reasons mentioned in the 'Introduction'. Whilst the former are based on $30 \mathrm{~s}$ time steps between each light level, the latter are based on 30 min time steps. However, the first values of PSII effective quantum efficiency $\left(\Phi_{\text {PSII }}\right)$ measured in each RLC may be viewed as a steady-state fluorescence response since algae had time to adapt for 20 to $30 \mathrm{~min}$ at each light level used in the oxygen incubations. Therefore, PAM-based SSLCs may be constructed from the first fluorescence reading of each RLC. These SSLCs are comparable to those obtained from the oxygen incubations. Other authors have used a similar approach to compare oxygen evolution with chlorophyll fluorescence, but they used different time steps at each light level. For example, Figueroa et al. (2003) used 5 to 10 min time steps. The approach followed in this work of combining RLCs with SSLCs is very similar to that described by Nitschke et al. (2012), except that they used 3 min steps at each light level to obtain the SSLCs, whereas, in the present study, we employed longer (30 min) time steps.

\section{Laminaria hyperborea blade steady-state PAM P-I curves}

A third experiment (Expt 3) was carried out to confirm some trends obtained in Expts 1 \& 2. In Expt 3, 4 replicate parts of L. hyperborea blades were kept in the incubators and subject to the previously described light levels, after which fluorescence measurements were taken. These algal fronds were collected on a later occasion (June 2012) in approximately the same depth range and area in which the first samples were obtained. After acclimation to each light level for a period of $30 \mathrm{~min}$, a saturation pulse was applied and $\Phi_{\text {PSII }}$ was measured. Algal pieces were kept at the bottom of the incubator to allow a homogeneous light environment. These measurements were used to determine PAM fluorescence SSLCs, similar to that described in the previous subsection, but only for L. hyperborea blades. 


\section{Data analysis}

P-I functions were fitted to experimental data using the following equation described by Jassby \& Platt (1976):

$$
\mathrm{GP}=P_{\max } \tanh \left(\frac{\alpha \times \mathrm{PAR}}{P_{\max }}\right)
$$

where GP is the gross oxygen production, $P_{\max }$ is the maximal production rate or photosynthetic capacity $\left(\mathrm{mg} \mathrm{O}_{2} \mathrm{~g}^{-1} \mathrm{DW} \mathrm{h}^{-1}\right.$ ) and $\alpha$ is the initial slope or photosynthetic efficiency $\left(\mathrm{mg} \mathrm{O}_{2} \mathrm{~g}^{-1} \mathrm{DW} \mathrm{h}^{-1} \mu \mathrm{mol}\right.$ photons $\mathrm{m}^{-2} \mathrm{~s}^{-1}$ ).

Knowing dark respiration (R), Eq. (1) may be solved for net production (NP):

$$
\mathrm{NP}=P_{\max } \tanh \left(\frac{\alpha \times \mathrm{PAR}}{P_{\max }}\right)-R
$$

Compensation light intensity $\left(\mathrm{PAR}_{\mathrm{C}}\right)$ may be calculated by solving Eq. (2) for PAR, when NP = 0 such that,

$$
\operatorname{PAR}_{\mathrm{C}}=\frac{\ln \left(\frac{P_{\max }+R}{P_{\max }-R}\right)}{2 \alpha}
$$

When photo-inhibition was apparent, the equation described by Eilers \& Peeters (1988) was used:

$$
\mathrm{GP}=\frac{\mathrm{PAR}}{a \times \mathrm{PAR}^{2}+b \times \mathrm{PAR}+c}
$$

In this case,

$$
\mathrm{PAR}_{\mathrm{C}}=\frac{-(R \times b-1) \pm \sqrt{(R \times b-1)^{2}-4 \times R^{2} \times a \times c}}{2 \times R \times a}
$$

where $a, b$ and $c$ are parameters that may be related with the usual P-I curve characteristics by the following formulas:

$$
\begin{gathered}
\mathrm{PAR}_{\mathrm{opt}}=\sqrt{\frac{c}{a}} \\
P_{\max }=\frac{1}{2 \sqrt{a \times c+b}} \\
\alpha=\frac{1}{c}
\end{gathered}
$$

and where $\mathrm{PAR}_{\text {opt }}$ is optimum light intensity (PAR) in $\mu \mathrm{mol} \mathrm{m} \mathrm{m}^{-2} \mathrm{~s}^{-1}$ photons, i.e. the light intensity that maximizes photosynthesis. This parameter is used when the $\mathrm{P}-\mathrm{I}$ relationship is parabolic, i.e. when in the presence of photoinhibition.

These equations were fitted to experimental data using non-linear regression with SPSS software (v.20). Equations from both experiments were used later to estimate GP at the exact light levels used in the Diving-PAM RLCs and to compare production values from the oxygen incubation experiments with those from the fluorescence RLCs.

In Expt 1, oxygen P-I curves were fitted separately with increasing and decreasing light levels and also to the whole dataset. P-I curves were compared by F-ratios, as described in Mead \& Curnow (1983), testing the significance of the increase in the mean square residuals when the same P-I curve is fitted to the whole dataset. The null hypothesis is that the P-I curves obtained with increasing and decreasing light levels do not differ significantly.

In Expt 2, a 2-way ANOVA was carried out using as independent factors 'time of day', with 3 levels (morning, midday and afternoon), 'light intensity' (repeated measurements) and their synergy. Furthermore, P-I curves were fitted separately to data obtained at each time of the day, and the test described above for the first experiment was performed following Mead \& Curnow (1983).

Fluorescence measurements were used to calculate the electron transport rate (ETR) and oxygen production (hereafter oxygen production based on fluorescence will be abbreviated as $\left.P_{\text {PSII }}\right)$ using the following equations according to other authors (e.g. Hancke et al. 2008):

$$
\begin{aligned}
& \mathrm{ETR}=\phi_{\mathrm{PSII}} \times E \times \mathrm{CF} \\
& P_{\mathrm{PSII}}=\mathrm{ETR} \times \Gamma
\end{aligned}
$$

where $\phi_{\text {PSII }}$ is the quantum yield of charge separations in PSII ( $\mu \mathrm{mol} \mathrm{e}^{-} \mu \mathrm{mol}$ photon ${ }^{-1}$ ); $E$ is absorbed radiance ( $\mu$ mol photons $\mathrm{m}^{-2} \mathrm{~s}^{-1}$ ), obtained from the product of incident PAR and blade or stipe absorption; $\Gamma$ is the stoichiometric ratio of oxygen evolved per electron generated at PSII - $0.25 \mathrm{O}_{2}\left(\mathrm{e}^{-}\right)^{-1}$ (Falkowski \& Raven 1997) and CF is a correction factor to account for the fraction of light that is absorbed by PSII. If $\Phi_{\text {PSII }}$ is obtained in a dark-adapted state, it measures the PSII maximum quantum efficiency, if it is obtained in a light-adapted state, it measures the effective PSII quantum efficiency.

A commonly used value for $\mathrm{CF}$ is 0.5 (Morris \& Kromkamp 2003), implying that light is equally distributed between PSI and PSII. Hancke et al. (2008) discuss the influence of the approach used to estimate the fraction of light absorbed by PSII when comparing PAM oxygen production estimates with those obtained from incubation experiments using different phytoplankton species. In the present study, the most usual approach was followed-it was assumed that absorbed light is equally distributed between PSI and PSII. The result of Eq. (10), ex- 
pressed in $\mu \mathrm{mol} \mathrm{O}_{2} \mathrm{~m}^{-2} \mathrm{~s}^{-1}$, was converted to $\mu \mathrm{mol} \mathrm{O}_{2}$ $\mathrm{g}^{-1} \mathrm{DW} \mathrm{h} \mathrm{h}^{-1}$ for comparability with data from the incubations (see 'Oxygen P-I curves') after determining the DW of circles of Laminaria hyperborea blades and stipes. L. hyperborea circles were cut with the same area of the circles illuminated by the DivingPAM USH, and the relationship between area and DW was determined.

The above calculations were carried out for the blades and stipes separately. To facilitate comparisons between fluorescence-based oxygen production estimates and those obtained from the incubations, a weighted oxygen production value was calculated for whole plants from the blade: stipe DW ratio of the plants used in the oxygen production incubations.

\section{RESULTS}

\section{Expt 1: effects of increasing/decreasing light shifts on photosynthetic rates}

Fig. 1A shows a typical plot of oxygen evolution in the incubators as a function of time and light intensity. At all light intensities and in all replicates, oxygen evolved linearly with time (not shown). Gross oxygen production showed a striking similarity between the increasing and the decreasing light shifts (Fig. 1B). The increase in mean square residuals resulting from fitting one equation to the whole dataset $(\alpha=0.006 \mathrm{mg}$ $\mathrm{O}_{2} \mathrm{~g}^{-1} \mathrm{DW} \mathrm{h}^{-1}$ umol photons $\mathrm{m}^{-2} \mathrm{~s}^{-1}$ and $P_{\max }=$ $1.8 \mathrm{mg} \mathrm{O}_{2} \mathrm{~g}^{-1} \mathrm{DW} \mathrm{h}^{-1}$ ), compared to fitting different equations to each one (increasing and decreasing) was not significant ( $p>0.05)$. Thus, the results suggest a symmetrical response to light in algae incubated for a period of several hours. $\mathrm{PAR}_{\mathrm{c}}$ estimated from Eq. (3) was $24.5 \mu \mathrm{mol}$ photons $\mathrm{m}^{-2} \mathrm{~s}^{-1}$. Average dark respiration was 0.18 and $0.33 \mathrm{mg} \mathrm{O}_{2} \mathrm{~g}^{-1} \mathrm{DW} \mathrm{h}^{-1}$ ) for the increasing and the decreasing light shifts, respectively.

Gross oxygen production estimated from fluorescence measurements $\left(P_{\mathrm{PSII}}\right)$ during the increasing and decreasing light phases of the first experiment showed that blade production was approx. one order of magnitude larger than that obtained for the stipes (Figs. 2 \& 3). Apart from blade and stipe RLCs, combined RLCs are also presented in the same figures and were calculated from a weighted average of blade and stipe $P_{\text {PSII }}$ based on the blade:stipe DW ratios. Photosynthetic parameters corresponding to these combined curves are depicted in Table 1. A clear pattern between acclimation light intensity and parameter values is not apparent, even though $P_{\max }$ shows maximal values after acclimation to the third highest light intensities $\left(212 \mu \mathrm{mol}\right.$ photons $\left.\mathrm{m}^{-2} \mathrm{~s}^{-1}\right)$, during the increasing and decreasing light shifts. A decrease in RLC $P_{\text {PSII }}$ was always observed at higher light levels (Figs. $2 \& 3$, Table 1), in contrast to what was observed in the oxygen incubation measurements (Fig. 1).
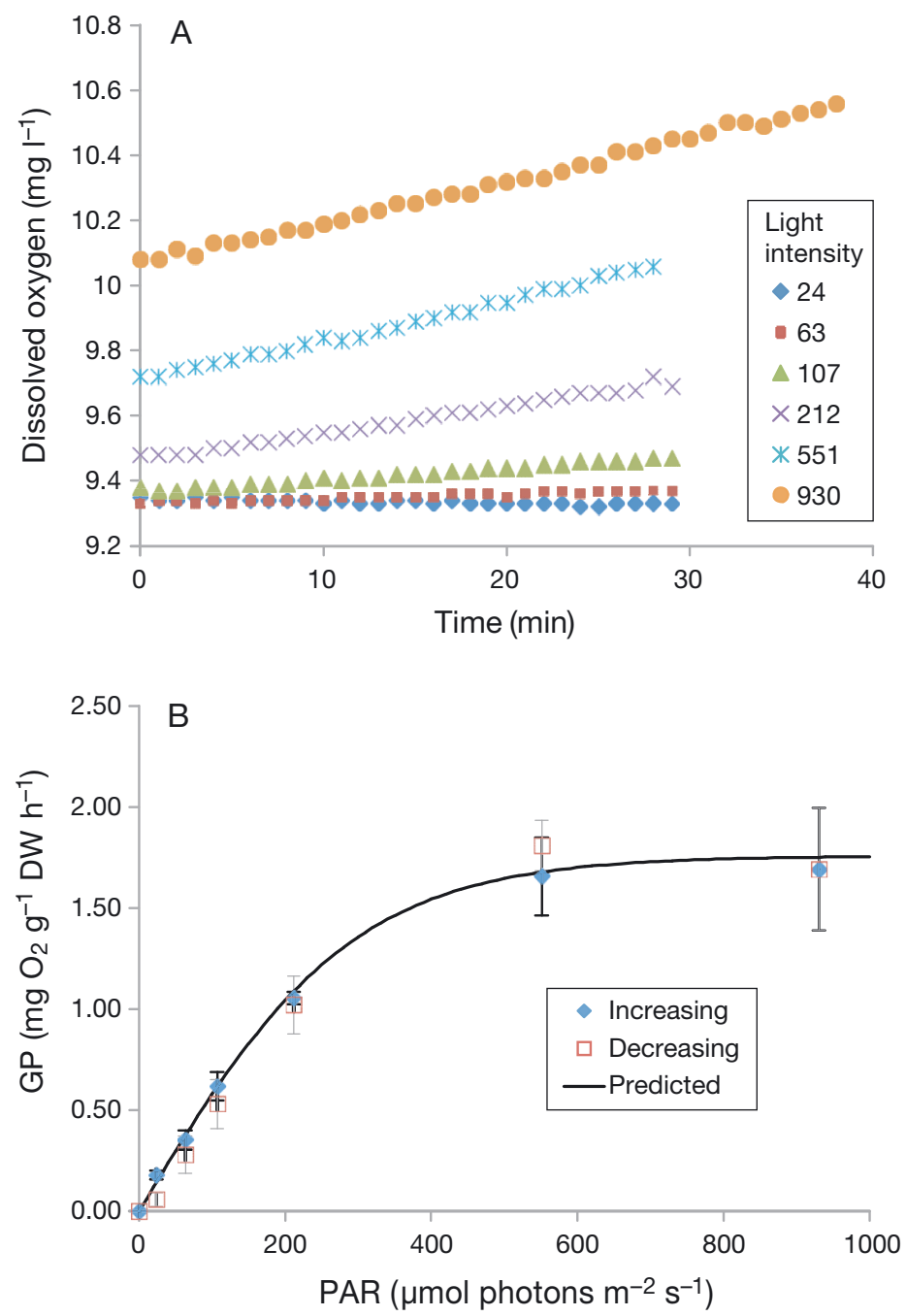

Fig. 1. Laminaria hyperborea. (A) Dissolved oxygen as a function of time in one of the incubators during the increasing light shift of Expt 1. Key indicates the PAR levels ( $\mu \mathrm{mol}$ photons $\mathrm{m}^{-2} \mathrm{~s}^{-1}$ ) corresponding to each dataset. Other replicates followed the same patterns. (B) Gross oxygen production (GP) $( \pm 95 \% \mathrm{CI})$ with increasing and decreasing light intensity shifts and fitted with the Jassby \& Platt (1976) equation $\left(P_{\max }=1.8 \mathrm{mg} \mathrm{O}_{2} \mathrm{~g}^{-1} \mathrm{DW} \mathrm{h}^{-1} ; \alpha=\right.$ $0.006 \mathrm{mg} \mathrm{O}_{2} \mathrm{~g}^{-1} \mathrm{DW} \mathrm{h} \mathrm{h}^{-1} \mu \mathrm{mol}$ photons $\mathrm{m}^{-2} \mathrm{~s}^{-1}$; compensation PAR $=24.6 \mu \mathrm{mol}$ photons $\mathrm{m}^{-2} \mathrm{~s}^{-1}$ ) 

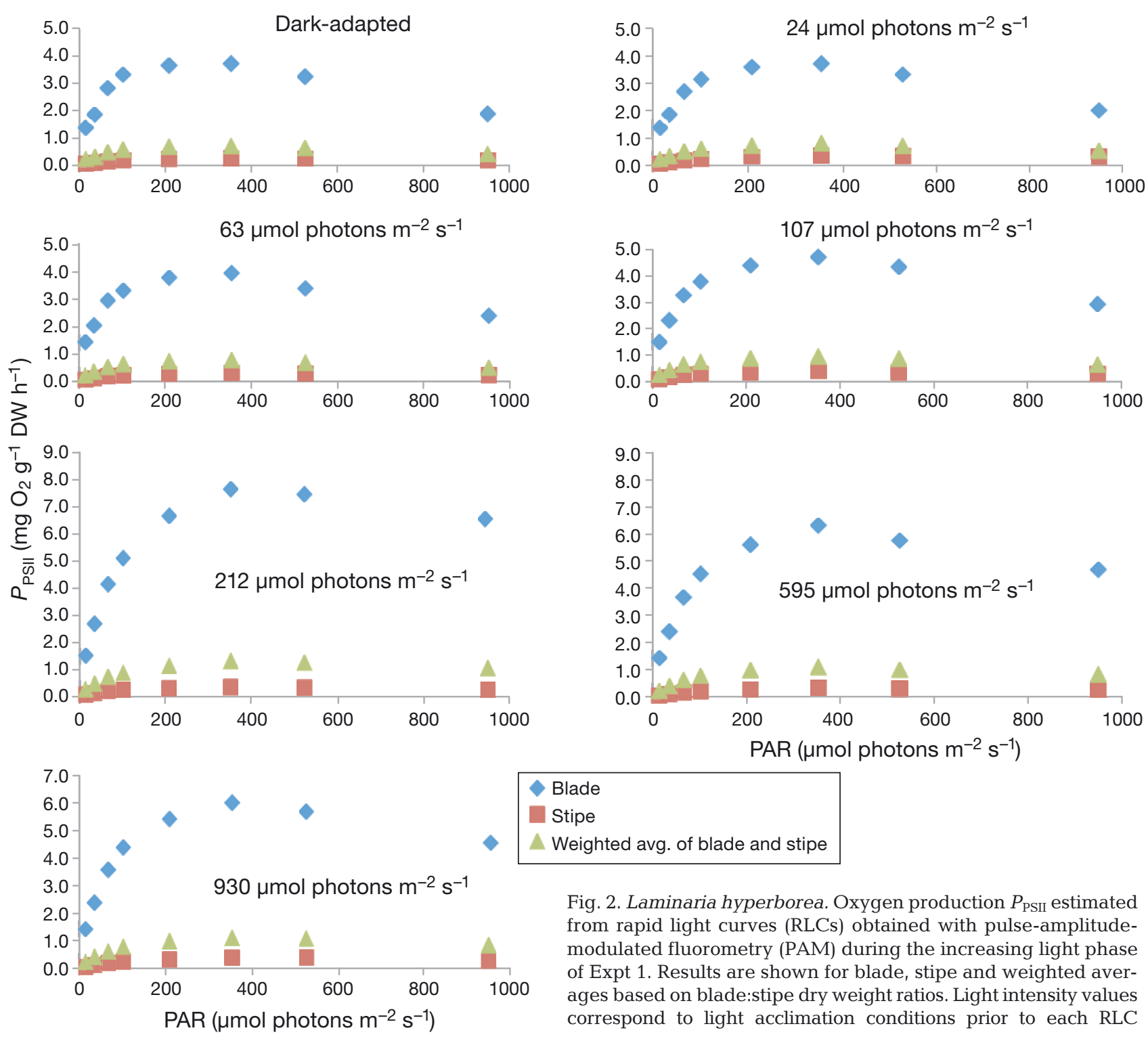

$P_{\text {PSII }}$ estimates from PAM SSLCs varied linearly with light intensity in Expt 1 (increasing and decreasing light; Fig. 4A), suggesting the absence of any saturation or inhibition of the effect of light. Calculated oxygen production values were extremely high when compared to estimates based on direct oxygen measurements (Fig. 1).

\section{Expt 2: diel variability of the P-I relationship}

Results are shown in Fig. 5, including the fitted lines obtained with the Jassby \& Platt (1976) equation for each dataset and their parameters. The variability among replicates was very large, and this is probably

the reason why the 2-way ANOVA led to acceptance of the null hypothesis about the absence of a significant 'time of day' effect, as well as a synergy between 'time of day' and 'light intensity' ( $p>0.05)$. However, when only one P-I function was fitted to all datasets, the increase in the mean square residuals was significant $(p<0.05)$, suggesting that P-I parameters were significantly different among the 3 datasets. $P_{\max }$ ranged from ca. 1.0 to $1.9 \mathrm{mg} \mathrm{O}_{2} \mathrm{~g}^{-1} \mathrm{DW} \mathrm{h}^{-1}$, being minimal at midday. $\mathrm{PAR}_{\mathrm{c}}$ values ranged from 20.2 to $27.4 \mu \mathrm{mol}$ photons $\mathrm{m}^{-2} \mathrm{~s}^{-1}$ from morning until the afternoon experiment. Average dark respiration was $0.35,0.16$ and $0.19 \mathrm{mg} \mathrm{O}_{2} \mathrm{~g}^{-1} \mathrm{DW} \mathrm{h}^{-1}$ ) for the morning, midday and afternoon incubations, respectively. 


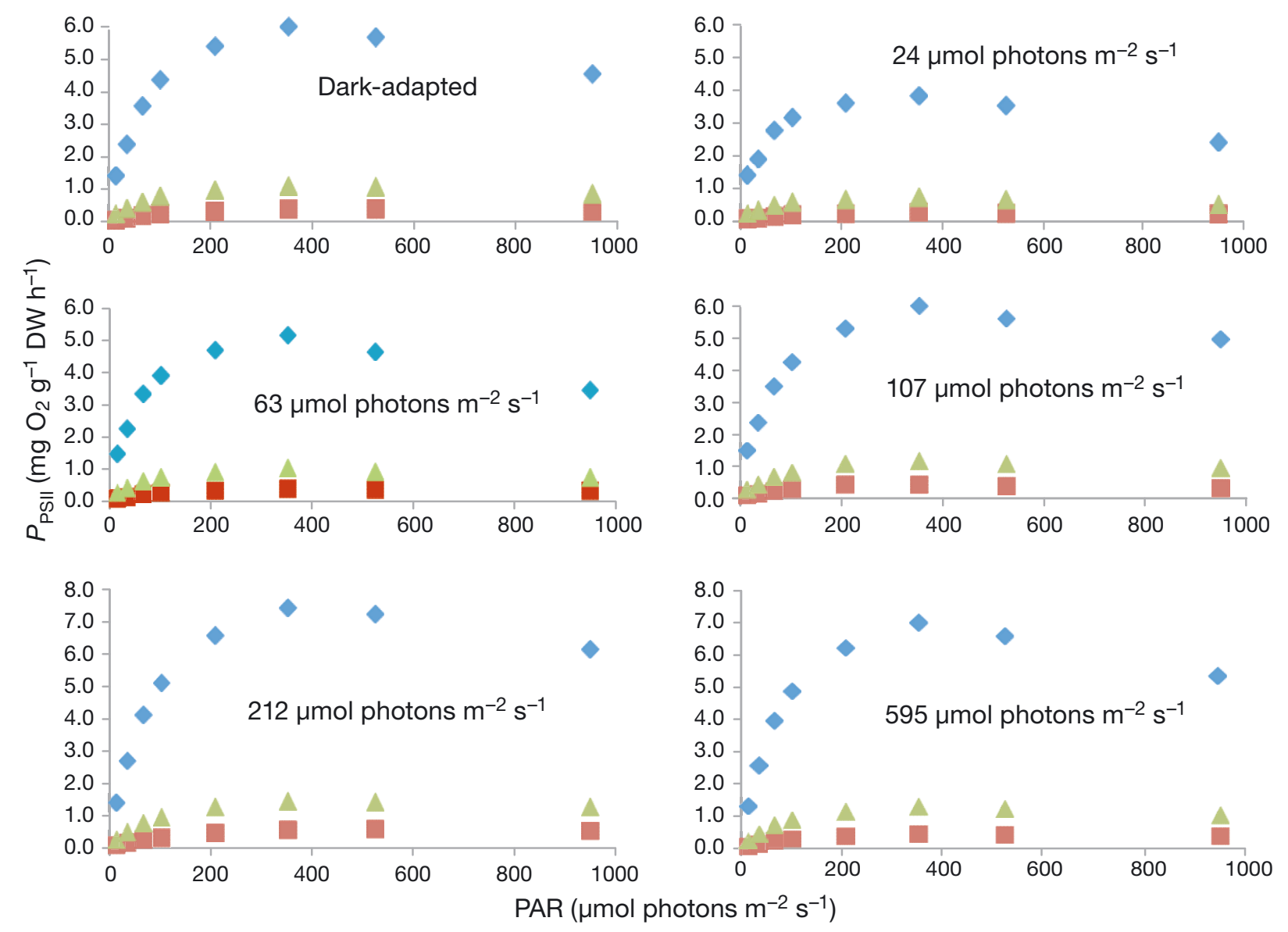

Fig. 3. Laminaria hyperborea. As for Fig. 2, but during the decreasing light phase of Expt 1 (order actually from the lower right to upper left panel)

Table 1. Laminaria hyperborea. Photosynthetic parameters for the rapid light curves depicted in Figs. 2 \& 3, corresponding to weighted averages of blade and stipe contributions based on their dry weight (DW) ratios. The first column contains the light levels ( $\mu \mathrm{mol}$ photons $\mathrm{m}^{-2} \mathrm{~s}^{-1}$ ) to which seaweeds were exposed prior to each RLC; $\alpha$ : initial slope or photosynthetic efficiency (mg $\mathrm{O}_{2} \mathrm{~g}^{-1} \mathrm{DW} \mathrm{h} \mathrm{h}^{-1} \mu \mathrm{mol}$ photons $\mathrm{m}^{-2} \mathrm{~s}^{-1}$ ); PAR $_{\text {opt }}$ : optimal PAR ( $\mu$ mol photons $\mathrm{m}^{-2} \mathrm{~s}^{-1}$ ); $P_{\max }$ : maximal production rate or photosynthetic capacity $\left(\mathrm{mg} \mathrm{O}_{2} \mathrm{~g}^{-1} \mathrm{DW} \mathrm{h}^{-1}\right)$

\begin{tabular}{|c|c|c|c|}
\hline Light levels & $\alpha$ & $\mathrm{PAR}_{\text {opt }}$ & $P_{\max }$ \\
\hline \multicolumn{4}{|c|}{ Increasing light shift } \\
\hline 0 & 0.01 & 230 & 0.7 \\
\hline 24 & 0.01 & 273 & 0.8 \\
\hline 63 & 0.02 & 253 & 0.8 \\
\hline 107 & 0.02 & 265 & 0.9 \\
\hline 212 & 0.02 & 395 & 1.3 \\
\hline 595 & 0.01 & 334 & 1.1 \\
\hline 930 & 0.01 & 351 & 1.1 \\
\hline \multicolumn{4}{|c|}{ Decreasing light shift } \\
\hline 595 & 0.02 & 364 & 1.2 \\
\hline 212 & 0.02 & 441 & 1.4 \\
\hline 107 & 0.02 & 355 & 1.1 \\
\hline 63 & 0.02 & 312 & 1.0 \\
\hline 24 & 0.02 & 276 & 0.7 \\
\hline 0 & 0.01 & 329 & 0.9 \\
\hline
\end{tabular}

The comparison between fluorescence blade and stipe data (not shown) showed similar trends to those described before for Figs. 2 \& 3. Once again, a decrease in photosynthesis was observed in the fluorescence data at high light intensities, in opposition to the saturation results obtained with oxygen incubation measurements. Combined blade:stipe RLCs were calculated as for the previous experiment, and the photosynthetic parameters obtained are depicted in Table 2. Generically, $\alpha$ and $P_{\max }$ decreased over the day, and PAR ${ }_{\text {opt }}$ did not show a clear pattern (Table 2).

$P_{\text {PSII }}$ estimates from PAM SSLCs varied almost linearly with light intensity for the morning, midday and afternoon incubations (Fig. 4B), suggesting the absence of any saturation or inhibition effect of light, as mentioned earlier for the first experiment. A slight curvature was apparent at higher light intensities, suggesting a departure from linearity that may be a sign of some incipient saturation phenomenon. Calculated oxygen production values were extremely high when compared to estimates based on direct oxygen measurements (Figs. 1 \& 5). 


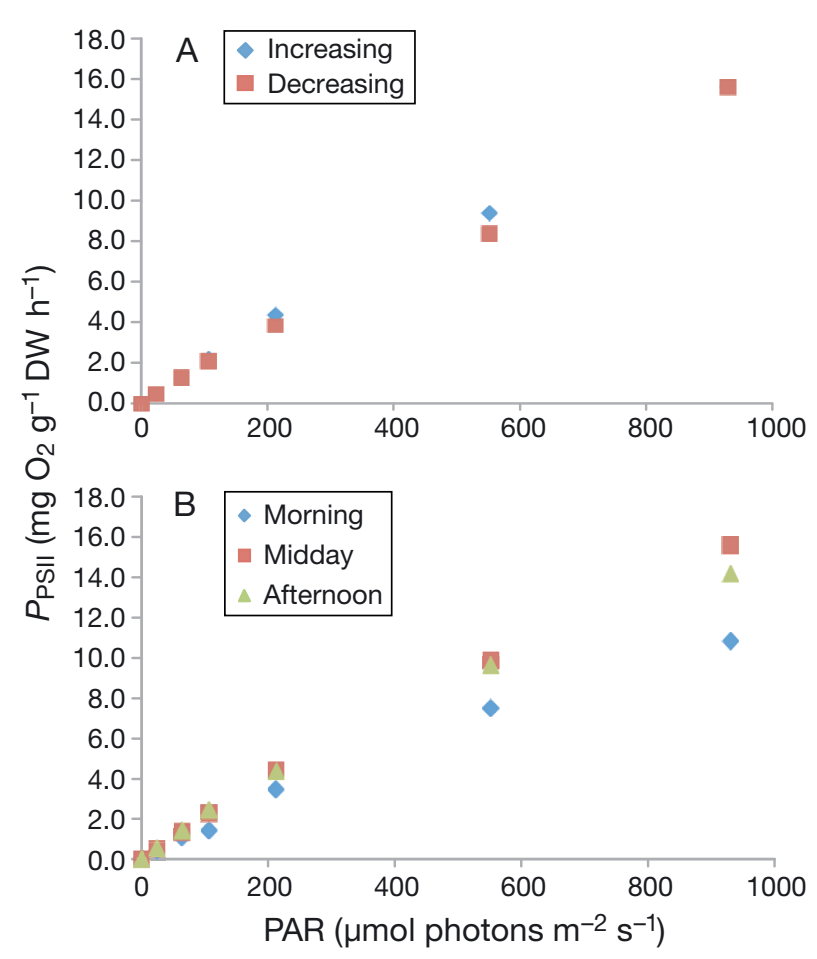

Fig. 4. Laminaria hyperborea. Oxygen production estimated from PAM steady-state photosynthesis-irradiance curves $\left(P_{\mathrm{PSII}}\right)$ during $(\mathrm{A})$ increasing and decreasing light intensity shifts (Expt 1) and (B) from morning, midday and afternoon incubations (Expt 2). Values are weighted averages of blade and stipe results, obtained from DW ratios

\section{Expt 3: Laminaria hyperborea blade steady-state PAM P-I curves}

ETR values are depicted in Fig. 6, together with results obtained for the previous experiments. In this case, only blade results are shown for the sake of comparability, since the third experiment was carried out using only blade sections. Strong similarity between all experiments was observed in spite of the increasing variability towards higher light intensities (Fig. 6).

\section{Incubations vs. PAM fluorescence}

When production results from Expt 1 measured under light intensities $>221 \mu \mathrm{mol}$ photons $\mathrm{m}^{-2} \mathrm{~s}^{-1}$ were excluded, there was a significant linear relationship - considering the F-ratio between explained and unexplained variance estimated with Model II regression following Laws \& Archie (1981), p < $0.001-$ between oxygen production estimated from PAM SSLCs and from incubations, with a slope close to 4 (Fig. 7, upper left graph). Concerning Expt 2 (Fig. 7,
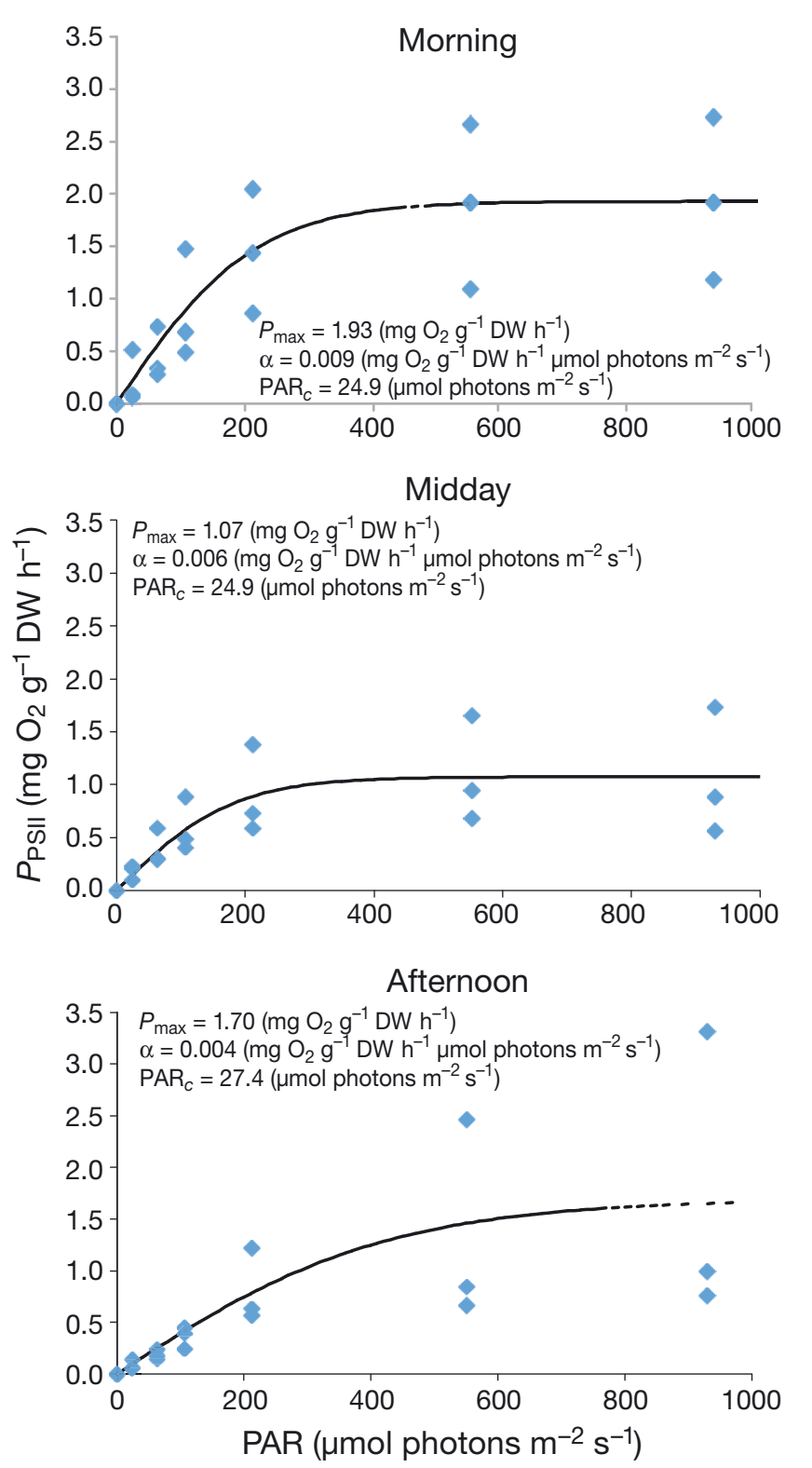

Fig. 5. Laminaria hyperborea. Observed and predicted gross oxygen production (GP) from morning, midday and afternoon incubation experiments (Expt 2) and fitted with the Jassby \& Platt (1976) equation. Photosynthetic parameters corresponding to the fitted line and light intensity compensation values $\left(\mathrm{PAR}_{\mathrm{c}}\right)$ are shown

lower left graph), significant linear trends were also observed $(\mathrm{p}<0.05)$ up to the above-mentioned light intensity threshold, with the slopes of the regressions lines (not shown) varying between 3.3 and 4.7. If, instead of correlating oxygen production from SSLCs with oxygen production from the incubations, ETR was correlated with the latter, similar patterns were obtained, since oxygen production estimated from SSLC is proportional to ETR. The slope of a regres- 


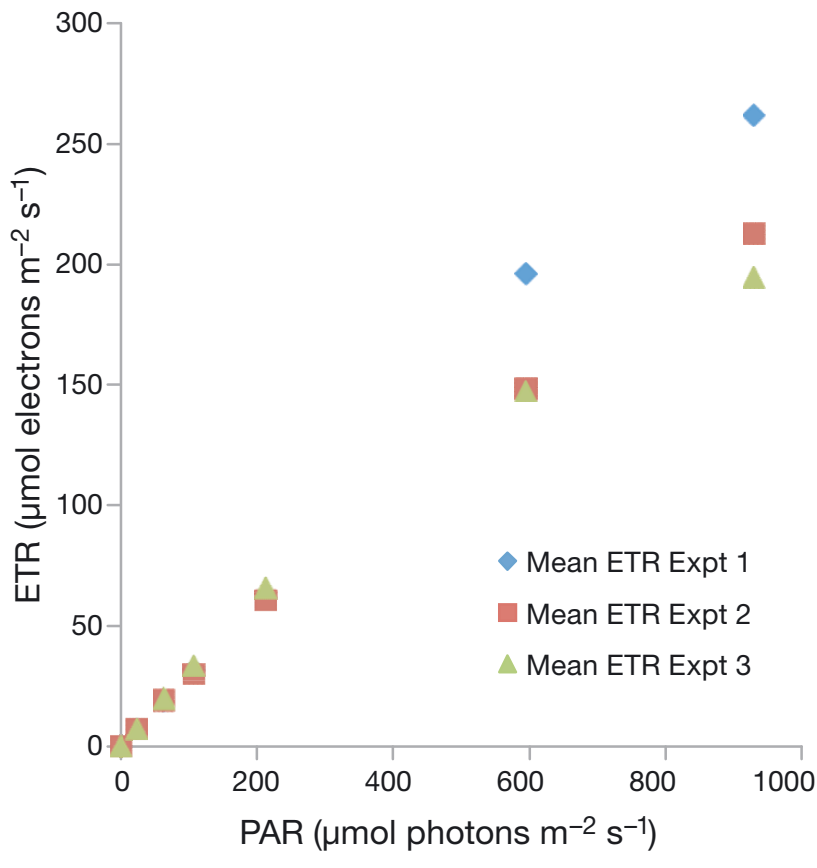

Fig. 6. Laminaria hyperborea. Steady-state electron transport rate (ETR) from PAM steady-state light curves obtained with the Diving-PAM for blades in all experiments

sion line between ETR and GP from the incubations, after converting GP to $\mu \mathrm{mol} \mathrm{O}_{2} \mathrm{~m}^{-2} \mathrm{~s}^{-1}$, is an indication of the number of excited electrons required to release 1 oxygen molecule. In Fig. 7, plots of ETR versus oxygen production are presented for Expts 1 \& 2 (upper and lower right graphs, respectively). The slope of the regression line between these variables was 5.4 for Expt 1 and between 2.1 and 6.5 for Expt 2, excluding values obtained under light intensities $>221 \mu \mathrm{mol}$ photons $\mathrm{m}^{-2} \mathrm{~s}^{-1}$, as before.

Figs. 8 \& 9 depict the relationship between oxygen production estimated from RLCs and from incubations for Expts $1 \&$ 2, respectively. There is a para- bolic relationship in all cases. Regression lines were obtained with a Model II linear regression, excluding values obtained $>102 \mu \mathrm{mol}$ photons $\mathrm{m}^{-2} \mathrm{~s}^{-1}$. All obtained regression lines were significant considering the $F$-ratio between explained and unexplained variance $(\mathrm{p}<0.001)$.

\section{DISCUSSION}

\section{P-I curves: methodological issues}

Macroalgae are capable of regulating photosynthetic activity to cope with light variability and to protect themselves against excessive light (Häder \& Figueroa 1997). This regulation poses several challenges in measuring and predicting photosynthetic activity, as mentioned before (cf. 'Introduction'). Considering the dynamic nature of the P-I relationship, it is expected that ambient light history will induce adjustments in the macroalgal photosynthetic apparatus and changes in the photosynthetic rate. Thus, if oxygen concentrations are measured over time, then a non-linear trend in oxygen evolution should be observed during the adjustment process. However, results from Expts 1 \& 2 did not show any noticeable deviation from linearity in oxygen evolution (Fig. 1A). The results presented are just an example, but similar trends were obtained with all replicates irrespective of light intensity (not shown), i.e. oxygen concentration within the incubation vessels increased linearly with time. Since oxygen measurements were taken every minute, any noticeable deviation from linearity would have to occur on a very short time scale (<1 min). These results seem to contradict the expected adjustments in photosynthetic parameters over the incubation time steps. Therefore, it may be hypothesized that, if any adjustments occurred in the

Table 2. Laminaria hyperborea. Photosynthetic parameters obtained for the rapid light curves (RLC) of Expt 2, corresponding to weighted averages of blade and stipe contributions based on their dry weight (DW) ratios. The first column contains the light levels to which seaweeds were exposed prior to each RLC; for abbreviations, see Table 1

\begin{tabular}{|c|c|c|c|c|c|c|c|c|c|}
\hline \multirow{2}{*}{$\begin{array}{l}\text { Light levels } \\
\text { ( } \mu \text { mol photons } \\
\left.\mathrm{m}^{-2} \mathrm{~s}^{-1}\right)\end{array}$} & \multicolumn{3}{|c|}{$\begin{array}{c}\alpha\left(\mathrm{mg} \mathrm{O}_{2} \mathrm{~g}^{-1} \mathrm{DW} \mathrm{h}^{-1}\right. \\
\left.\mu \mathrm{mol} \text { photons } \mathrm{m}^{-2} \mathrm{~s}^{-1}\right)\end{array}$} & \multicolumn{3}{|c|}{$\begin{array}{c}\text { PAR }_{\text {opt }} \\
\left(\mu \mathrm{mol} \text { photons } \mathrm{m}^{-2} \mathrm{~s}^{-1}\right)\end{array}$} & \multicolumn{3}{|c|}{$\begin{array}{c}P_{\max } \\
\left(\mathrm{mg} \mathrm{O}_{2} \mathrm{~g}^{-1} \mathrm{DW} \mathrm{h}^{-1}\right)\end{array}$} \\
\hline & Morning & Midday & Afternoon & Morning & Midday & Afternoon & Morning & Midday & Afternoon \\
\hline 0 & 0.0192 & 0.0160 & 0.0132 & 174.1 & 312.2 & 369.0 & 0.69 & 0.92 & 0.92 \\
\hline 24 & 0.0199 & 0.0153 & 0.0141 & 337.1 & 463.8 & 324.2 & 1.33 & 1.18 & 0.91 \\
\hline 63 & 0.0179 & 0.0170 & 0.0137 & 261.9 & 258.4 & 336.1 & 0.89 & 0.74 & 0.65 \\
\hline 107 & 0.0161 & 0.0161 & 0.0171 & 326.1 & 317.1 & 309.1 & 2.00 & 0.85 & 1.01 \\
\hline 212 & 0.0252 & 0.0158 & 0.0160 & 306.8 & 312.3 & 266.0 & 1.06 & 0.85 & 0.74 \\
\hline 551 & 0.0189 & 0.0132 & 0.0135 & 401.7 & 380.4 & 295.4 & 1.86 & 1.07 & 0.91 \\
\hline 930 & 0.0147 & 0.0120 & 0.0117 & 255.2 & 351.2 & 313.1 & 1.08 & 0.84 & 0.94 \\
\hline
\end{tabular}



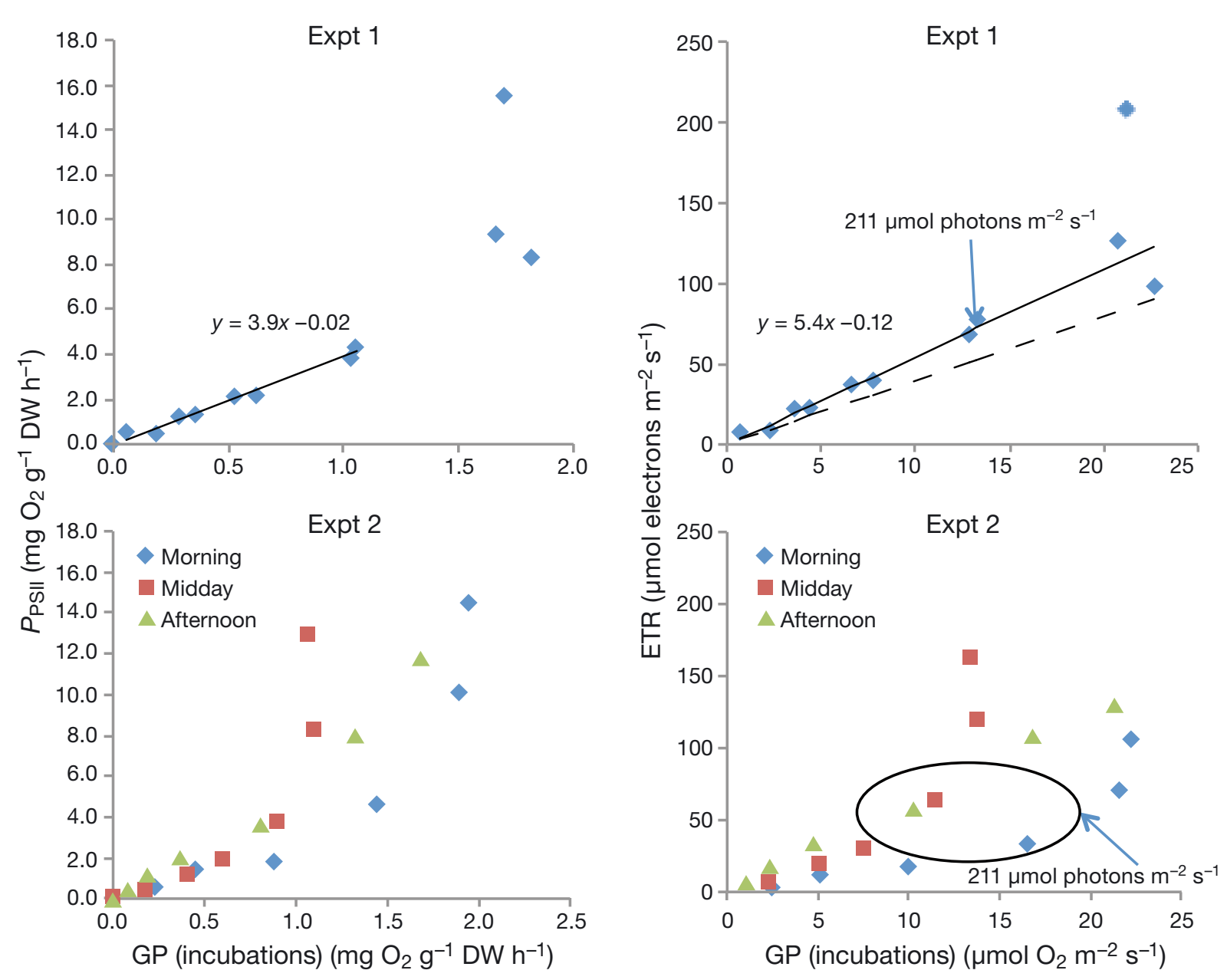

Fig. 7. Laminaria hyperborea. Left panels: oxygen production $\left(P_{\mathrm{PSII}}\right)$ estimated from PAM steady-state light curves (SSLCs) versus oxygen production estimated from incubation experiments for Expts 1 and 2. Right panels: electron transport rate (ETR) estimated from PAM SSLCs versus gross oxygen production (GP) estimated from incubation experiments for Expts 1 and 2. Upper panels: Expt 1, with increasing/decreasing light shifts. Points are the observed results and the continuous line shows the Model II linear regression. The dashed line shows the expected 4:1 ratio between ETR and oxygen production. Lower panels: Expt 2, with incubations carried out in the morning, at midday and in the afternoon. The light intensity above which the linearity between ETR and GP is lost is indicated in the right panels

photosynthetic apparatus during the incubations, they did not change the photosynthetic parameters. How can this hypothesis be reconciled with the frequently observed short-term photo-protective adjustments to high light levels, such as changes in the PSII cross section and non-photochemical quenching (e.g. Falkowski \& Raven 1997, Belshe et al. 2007)? A possible explanation is that these short-term changes may not change P-I parameters, e.g. $P_{\max }$ and $\alpha$, but may, instead, contribute to stabilize their values. This does not mean that photosynthetic parameters do not change at all, but, possibly, these changes only become 'visible' at longer time scales. If this is true, then the sort of oxygen incubations used in this study may lead to reliable estimates of photosynthetic parameters over a time scale of a few hours (ca. $3 \mathrm{~h}$ ).

\section{Expt 1: effects of increasing/decreasing light shifts on photosynthetic rates}

The similarity between P-I curves obtained with increasing and decreasing light shifts supports the above hypothesis (Fig. 1B), suggesting that the light sequence did not have a significant influence on the results. The similarity of the PAM SSLC results obtained with increasing and decreasing light shifts (Fig. 4A) was consistent with the oxygen incubation results. The $\alpha$ and $P_{\max }$ parameters from increasing and decreasing RLCs (Table 1) also exhibited some similarity, but the lack of replication prevents any solid conclusions. These patterns differ from those reported for benthic diatoms (Perkins et al. 2006), where increasing and decreasing RLCs produced asymmetrical photosynthetic responses. 


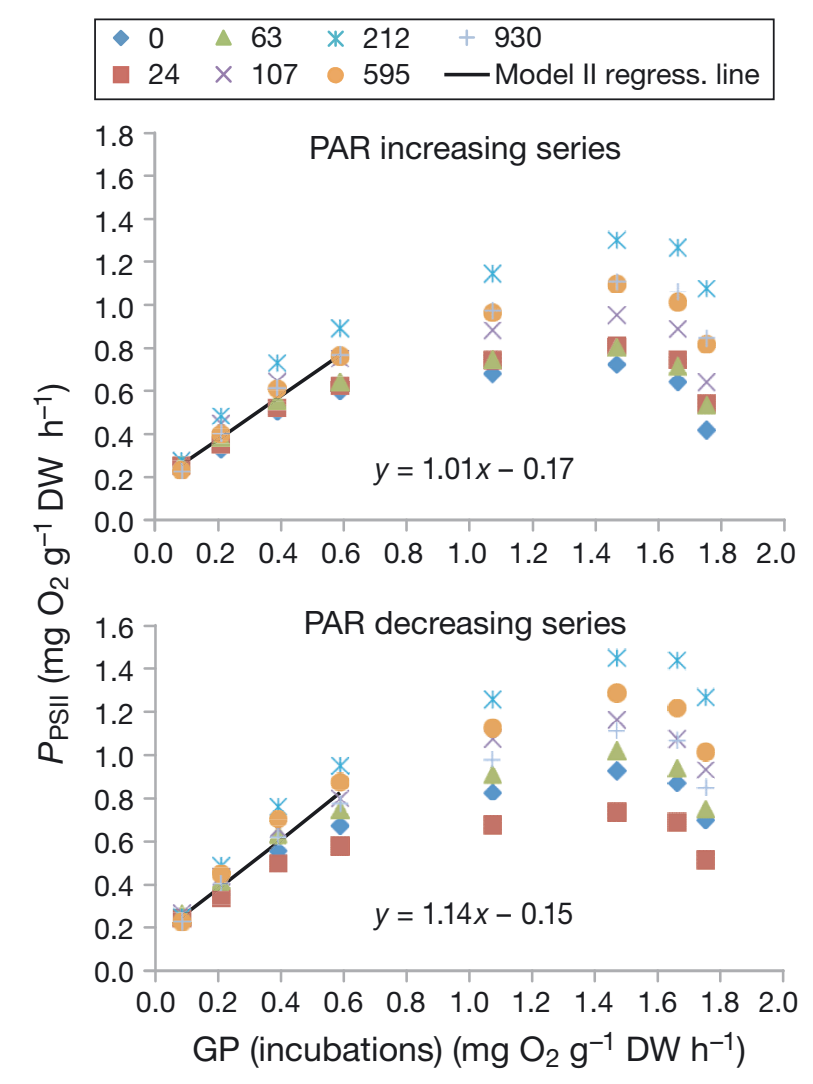

Fig. 8. Laminaria hyperborea. Oxygen production $\left(P_{\mathrm{PSII}}\right)$ estimated from RLCs versus gross oxygen production (GP) estimated from incubation experiments, with increasing and decreasing light shifts (see Fig. 1). Points are the observed results, and the continuous line shows the Model II linear regression between both datasets, excluding values obtained $>102 \mu \mathrm{mol}$ photons $\mathrm{m}^{-2} \mathrm{~s}^{-1}$

\section{Expt 2: diel variability of the P-I relationship}

The differences in P-I curves from the second experiment, i.e. morning, midday and afternoon incubations (non-significant with ANOVA, but significant with the method described by Mead \& Curnow [1983]) were inconclusive concerning the possible daily changes in P-I parameters due to the large error variance (Fig. 5). This large error variance may be a consequence of the variability in stipe and blade sizes and their physiological status, suggesting that more replication is needed in future experiments. Other authors have observed daily changes in oxygen and fluorescence P-I responses in macroalgae, mostly related to ambient light variation and photo-inhibition responses and not endogenous patterns like the ones that were tested in the current study (e.g. Hanelt at al. 1993, Sagert et al. 1997, Flores-Moya et al. 1998, Gévaert et al. 2003). Gévaert et al. (2003) showed that in Laminaria saccharina the
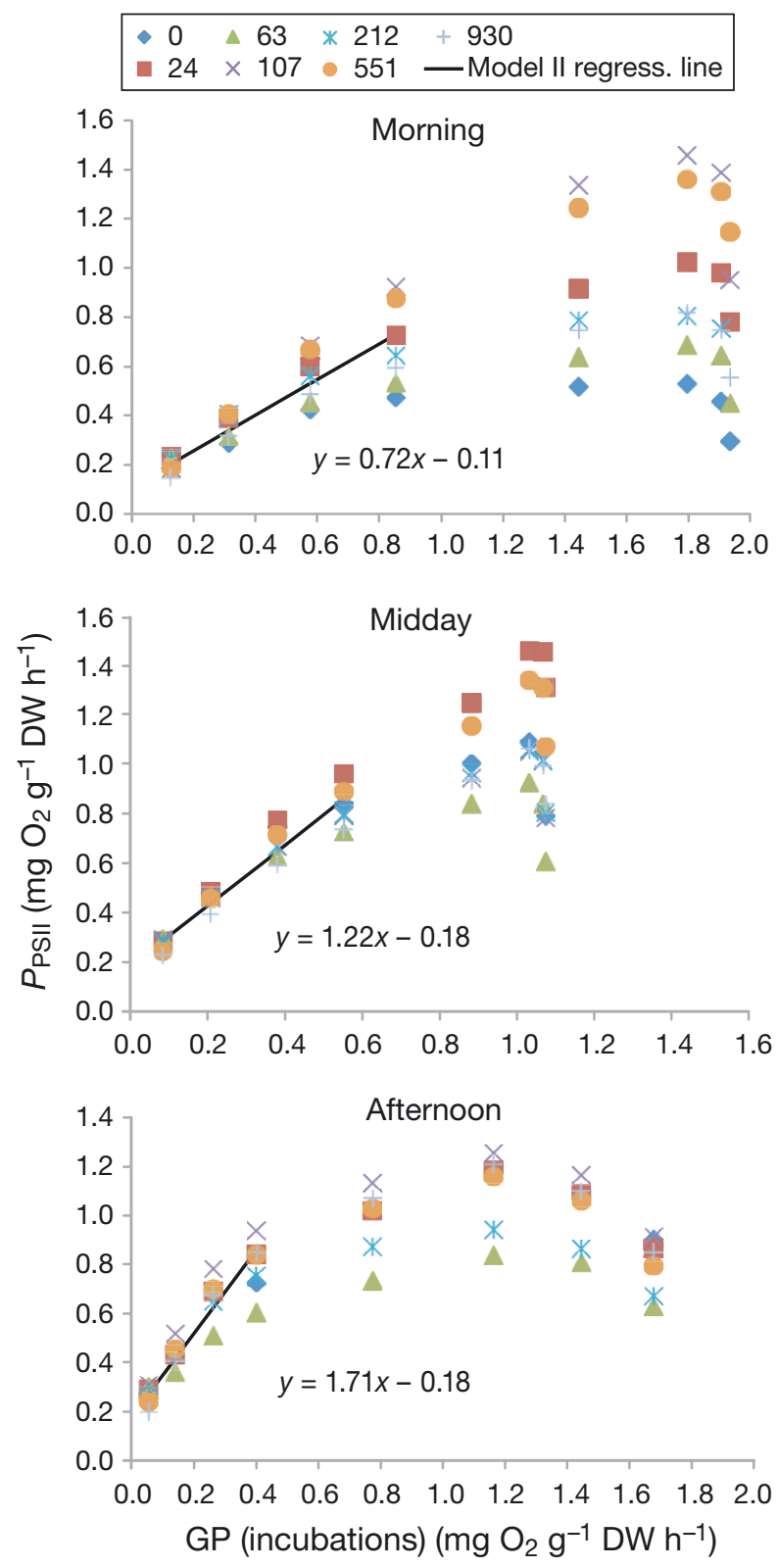

Fig. 9. Laminaria hyperborea. As for Fig. 8, but from incubation experiments conducted at morning, midday and afternoon

daily patterns in PAM fluorescence are related to photo-regulation via the xanthophyll cycle.

\section{Oxygen production/consumption rates}

Photosynthesis light saturation values obtained in Expts $1 \& 2$ were around $600 \mu \mathrm{mol}$ photons $\mathrm{m}^{-2} \mathrm{~s}^{-1}$, a value much higher than the $150 \mu \mathrm{mol}$ photons $\mathrm{m}^{-2} \mathrm{~s}^{-1}$ reported by Lüning (1979) for Laminaria hyperborea kelp blades using gas exchange experiments with 
small circles. The same author obtained $P_{\max }$ values of around $30 \mathrm{ml} \mathrm{O}_{2} \mathrm{dm}^{-2} \mathrm{~h}^{-1}$, corresponding to ca. $50 \mathrm{mg}$ $\mathrm{O}_{2} \mathrm{~g}^{-1} \mathrm{DW} \mathrm{h}{ }^{-1}$, assuming a DW:area ratio similar to

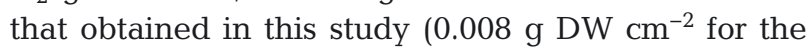
blades). This is $>1$ order of magnitude higher than the values obtained in the present study, with $P_{\max }$ not exceeding $2 \mathrm{mg} \mathrm{O}_{2} \mathrm{~g}^{-1} \mathrm{DW} \mathrm{h}{ }^{-1}$. If calculations are done assuming a dry weight:area ratio for whole fronds in the range of 0.012 to $0.0329 \mathrm{~g} \mathrm{~cm}^{-2}$ (cf. Table 3 in Lüning 1979), $P_{\max }$ would be in the range of 12 to $32 \mathrm{mg}$ $\mathrm{O}_{2} \mathrm{~g}^{-1} \mathrm{DW} \mathrm{h}{ }^{-1}$, still much higher than our estimates. $P_{\max }$ values from oxygen incubations obtained in the current study integrate the blade and stipe. $P_{\max }$ estimations using RLCs from the blade alone (Fig. 2) may reach values $>7 \mathrm{mg} \mathrm{O}_{2} \mathrm{~g}^{-1} \mathrm{DW} \mathrm{h}^{-1}$-still considerably lower than the estimations by Lüning (1979), yet closer to the $12 \mathrm{mg} \mathrm{O}_{2} \mathrm{~g}^{-1} \mathrm{DW} \mathrm{h}^{-1}$ value obtained when considering the higher limit of the dry weight:area ratio. Lüning (1979) measured L. hyperborea dark respiration values ranging from 0.19 to $0.70 \mathrm{ml} \mathrm{O}_{2} \mathrm{dm}^{-2} \mathrm{~h}^{-1}$. These values correspond to roughly 0.02 and $0.06 \mathrm{mg}$ $\mathrm{O}_{2} \mathrm{~g}^{-1} \mathrm{DW} \mathrm{h}{ }^{-1}$, values which are much lower than those obtained in the present study, i.e. 0.16 to $0.35 \mathrm{mg}$ $\mathrm{O}_{2} \mathrm{~g}^{-1} \mathrm{DW} \mathrm{h}^{-1}$ (Expts $1 \& 2$ ). These differences suggest that there may be considerable variability among kelps of the same or similar species and that net production of the individuals studied by Lüning (1979) was considerably higher than that obtained for individuals in the current study. These discrepancies might partially be explained by the usage of small pieces of Laminaria blades in most of the work cited above, in comparison to the usage of whole fronds in the present study. In fact, blade photosynthetic activity seems much higher than that of the stipe, leading to a possible overestimation of photosynthesis if results are extrapolated from the blade to whole specimens.

From SeaWiFS Level 3 PAR data, average surface light intensity in the study region in 2010 may be estimated at $453 \mathrm{umol}$ photons $\mathrm{m}^{-2} \mathrm{~s}^{-1}$. Therefore, the $\mathrm{PAR}_{\mathrm{c}}$ values obtained in Expts 1 \& 2 (around $20 \mu \mathrm{mol}$ photons $\mathrm{m}^{-2} \mathrm{~s}^{-1}$ ) corresponded to roughly $4 \%$ of PAR at sea level. This value is higher than the estimations by Kain (1971) and Kain et al. (1976) (1.0 to $1.9 \%$ of PAR at sea level) and by Lüning \& Dring (1979), near Helgoland (North Sea), where Laminaria hyperborea lived to depths of $8 \mathrm{~m}$, receiving $0.7 \%$ of visible surface irradiance. Kelps collected in the present study were observed to ca. $12 \mathrm{~m}$ depth, presumably because water is more transparent in this region than off Helgoland. Light intensities in excess of $200 \mu \mathrm{mol}$ $\mathrm{m}^{-2} \mathrm{~s}^{-1}$ at noon were measured in the same depth range and area in which $L$. hyperborea fronds were collected for this study.

\section{Oxygen incubations vs. PAM fluorescence}

The comparison between oxygen production based on incubations and the estimations from PAM SSLCs shows that the former saturated around $600 \mu \mathrm{mol}$ photons $\mathrm{m}^{-2} \mathrm{~s}^{-1}$ and the latter exhibited a linear or almost linear behavior with light, leading to oxygen production estimates much higher than those actually measured in the incubations (Figs. 1B, 4 \& 5). These results suggest that there is some sort of uncoupling between excitation energy in PSII and oxygen production or some other pathways of oxygen consumption proportional to light intensity (Falkowski et al. 1986, Prasil et al. 1996).

All slopes between ETR estimated from PAM SSLCs and oxygen production from the incubations (Fig. 7) were above the theoretical value of 4 , except for the results of Expt 2 in the morning, when the slope was 2.1. Figueroa et al. (2003) found values $<4$ for Ulva olivascens and $U$. rotundata. One possible source of calculation error in the present study may have been the weights of blade and stipe contributions used in calculating the dry weight: area ratios necessary to convert GP from milligrams of DW per gram per hour to micromoles of $\mathrm{O}_{2}$ per square meter per second and in integrating blade and stipe fluorescence results for a whole frond from the blade:stipe dry weight ratios. Flameling \& Kromkamp (1998) found considerable variability in the ETR:oxygen production ratio, studying 4 different microalgae, and suggested 2 possible interpretations for this variability: (1) one is that net oxygen production is influenced by processes that consume oxygen or affect electron transport, such as the Mehler reaction, Rubisco oxygenase activity and light-dependent mitochondrial respiration, or cyclic electron flow around PSII; or (2) the other is that saturating light causes changes in photosynthesis turnover time that do not match changes in fluorescence. The results of Flameling \& Kromkamp (1998) are consistent with those of Goto et al. (2008), also working with phytoplankton. In contrast, Beer et al. (2000) found that ETRs correlate linearly with gross oxygen rates and that the average molar $\mathrm{O}_{2}$ :ETR ratio is close to the theoretical value of 0.25 up to irradiances of $608 \mu \mathrm{mol}$ photons $\mathrm{m}^{-2} \mathrm{~s}^{-1}$. The loss of correlation between ETR and oxygen production as irradiance increases from limiting to saturating restricts the application of this technique for measuring macroalgal photosynthesis (Franklin \& Badger 2001). The patterns described here were similar to those observed in $U$. lactuca (Longstaff et al. 2002) and in U. rotundata, U. olivascens and Porphyra leu- 
costica (Figueroa et al. 2003), i.e. linear relationships between ETR and oxygen evolution were observed only for sub-saturation irradiances (Fig. 7). Calculated molar ratios between ETR values and the oxygen produced also deviated from the theoretical values reported in Longstaff et al. (2002), varying from 6.5 to 8.2. Estimates presented in Figueroa et al. (2003) deviated less from theoretical values than those presented in Longstaff et al. (2002) and in the present study. However, Figueroa et al. (2003) worked with small thallus pieces and did not attempt to integrate whole specimens as was done in this work. According to those authors, the relation between the moles of electrons (ETR) per mole of oxygen drastically increases at high irradiances, because electron sinks are very active, while oxygen production reaches a steady state.

Other examples can be found of comparisons between PAM-based oxygen production estimates being higher than those obtained from incubation experiments (e.g. Franklin \& Badger 2001) as well as lower (e.g. Hancke et al. 2008). The Franklin \& Badger proposed PSII cyclic electron flow as a possible explanation for their results. The latter authors explained their estimates as a result of the assumption that light is equally distributed between PSI and PSII, i.e. a 0.5 value for CF (Eq. 1). Results obtained in the current work suggest that up to about $200 \mu \mathrm{mol}$ photons $\mathrm{m}^{-2} \mathrm{~s}^{-1}$, PAM steady-state ETR values may be a good predictor of oxygen production. It was inconclusive whether the slope variability in Expt 2 was a result of intraspecific variability or a result of acclimation. Maximal ETR values depicted in Fig. 6 and obtained for the 3 experiments were larger than most values found in the literature, but comparable to estimates reported by Aamot (2011) for Laminaria digitata.

RLCs from Expts 1 \& 2 (Fig. 2, Tables 1 \& 2) showed a large difference between blade and stipe ETRs and oxygen production, with blade values being, approximately, one order of magnitude larger than stipe values, in spite of the usually higher stipe absorptances. Moreover, the difference between blades and stipes increased with light intensity. Probably, this was a result of the larger blade surface:volume ratio and a larger proportion of photosynthetic cells compared with the stipe. These results reinforce the importance of performing PAM measurements in different parts of the thallus of laminarian algae in ecologically oriented research. Increasing replication requires more measuring time, thus complicating in situ applications of submersible PAM fluorometers that are normally restricted by Scuba diver safety limits.
Another important aspect of RLCs is related to the length of the light steps between the saturating pulses that vary considerably in the literature. Ihnken et al. (2010) found up to 3-fold increases in maximal relative ETRs with increasing light step duration, from 10 to $90 \mathrm{~s}$. In this study, a $30 \mathrm{~s}$ step was used after a preliminary survey, with values ranging from $10 \mathrm{~s}$ to $1.5 \mathrm{~min}$. These results showed that time steps $<30 \mathrm{~s}$ usually led to lower ETRs, suggesting incomplete recovery of reaction centers, whereas time steps $>30 \mathrm{~s}$ did not lead to large ETR changes. Therefore, $30 \mathrm{~s}$ was chosen as a compromise between maximizing ETR and minimizing the time needed to obtain a RLC. These light steps are practicable in the laboratory but may not be feasible in underwater in situ conditions, since each RLC will take 4 min and holding the PAM and the sample holder for such a period of time is difficult under current and wave action.

All obtained RLCs exhibited a decrease in photosynthesis at light intensities above ca. $400 \mu \mathrm{mol}$ photons $\mathrm{m}^{-2} \mathrm{~s}^{-1}$. Contrastingly, fluorescence SSLC measurements never showed saturation or photoinhibition (Figs. 4 \& 6), suggesting that algae acclimated to different light levels for periods between 20 and 30 min become acclimated to that light and are capable of keeping high ETRs. However, as discussed earlier, this high ETR did not seem to be linearly coupled with oxygen production, and SSLC may only be a good oxygen production predictor at sub-saturating irradiances. One important question is: Are RLCs a good predictor of oxygen production? The problem here is that, due to the different time scales, oxygen incubations were not directly comparable to RLC. However, it is interesting to note that RLC oxygen production estimations and those from the incubations showed significant linear relationships when values $>102 \mu \mathrm{mol}$ photons $\mathrm{m}^{-2} \mathrm{~s}^{-1}$ were excluded (Figs. 8 \& 9). In summary, linear relationships were obtained between oxygen-incubationbased GP and $P_{\text {PSII }}$ from SSLCs and RLCs. However, these relationships were limited to lower light thresholds in the latter than in the former. The results presented here regarding RLCs and their comparisons with oxygen production from incubation experiments may be compared with those of Nielsen \& Nielsen (2008). These authors used time steps of 1 and 12 min at each light level to obtain the RLCs and to measure oxygen evolution, respectively. They observed that, at high light intensities, the ratio between $\mathrm{O}_{2}$ production and ETR decreased, which is not consistent with the results presented herein, where the parabolic relationship between oxygen production calculated from the incubation experi- 
ments and that estimated from RLCs suggests the opposite trend.

The data in Table 2 reveal some patterns that are in accordance with results obtained by other authors: $\alpha$ is always larger in the morning, except for the RLC obtained after exposure to $107 \mu \mathrm{mol}$ photons $\mathrm{m}^{-2} \mathrm{~s}^{-1}$, which is consistent with the results for Laminaria saccharina (Gévaert et al. 2003) and for the seagrass Thalassia testudinum (Belshe et al. 2007). As con-

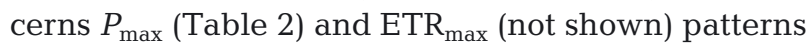
related to light intensity exposure were not clear, and the results from previous authors reveal different trends among them, which makes it difficult to establish an 'expected' pattern.

\section{CONCLUSIONS}

Results obtained in this work from oxygen-based production measurements suggest that P-I measurements were independent of the light sequences carried out. No clear conclusion could be found about the effects of measuring $\mathrm{P}-\mathrm{I}$ curves at different times of day on the curve parameters, but there was reasonable evidence in favor of significant daily variability in photosynthetic responses to light. When oxygen-based P-I responses are compared with both PAM RLC- and SSLC-based responses, linear trends were obtained only for sub-saturating irradiances, as observed previously by several other authors. Therefore, PAM RLCs and SSLCs may be used to predict oxygen production under those irradiances. Oxygen evolution in incubation vessels suggests that Laminaria hyperborea P-I curve parameters remain stable during oxygen incubations lasting ca. $3 \mathrm{~h}$ and that, if any adjustment in the photosynthetic apparatus takes place at this time scale, it probably does not change photosynthetic parameters, but, instead, tends to stabilize them. Thus, such a time scale may be appropriate to study P-I curves with oxygen incubations, and properly replicated experiments may be designed to get more insight into variability at larger time scales. The results of such experiments may provide feedback for mathematical models appropriate for calculating primary production in field conditions.

Acknowledgements. This work was funded by FEDER through the program COMPETE and by Portuguese authorities through the Science and Technology Foundation (Fundação para a Ciência e Tecnologia) (Project PTDC/MAR/ 111011/2009-Seamount benthic primary production: a new hypothesis to explain abundance and biodiversity over shallow seamounts [GreenMount]). B. Jesus was funded by a Pays de la Loire post-doctoral grant.

\section{LITERATURE CITED}

Aamot IA (2011) How photosynthesis in Laminaria digitata and Saccharina latissima is affected by water temperature. MS thesis, Norwegian University of Science and Technology, Trondheim

> Beer S, Larsson C, Poryan O, Axelsson L (2000) Photosynthetic rates of Ulva (Chlorophyta) measured by pulse amplitude modulated (PAM) fluorometry. Eur J Phycol 35:69-74

Belshe EF, Durako MJ, Blum JE (2007) Photosynthetic rapid light curves (RLC) of Thalassia testudinum exhibit diurnal variation. J Exp Mar Biol Ecol 342:253-268

Blache U, Jakob T, Su W, Wilhelm C (2011) The impact of cell-specific absorption properties on the correlation of electron transport rates measured by chlorophyll fluorescence and photosynthetic oxygen production in planktonic algae. Plant Physiol Biochem 49:801-808

> Davison IR (1991) Environmental effects on algal photosynthesis: temperature. J Phycol 27:2-8

$>$ Dromgoole FI (1978a) The effects of $\mathrm{pH}$ and inorganic carbon on photosynthesis and dark respiration of Carpophyllum (Fucales Phaeophyceae). Aquat Bot 4:11-22

Dromgoole FI (1978b) The effects of oxygen on dark respiration and apparent photosynthesis of marine macro-algae. Aquat Bot 4:281-297

Duarte P (2005) Photosynthesis-irradiance relationships in marine microalgae, Chap 17, Vol 2. In: Subba Rao DV (ed) Algal cultures analogues of blooms and applications. Science Publishers, Enfield, NH, p 639-670

- Eilers PHC, Peeters JCH (1988) A model for the relationship between light intensity and the rate of photosynthesis in phytoplankton. Ecol Modell 42:199-215

Falkowski PG, Raven JA (1997) Aquatic photosynthesis. Blackwell, Oxford

Falkowski PG, Fujita Y, Ley A, Mauzerall D (1986) Evidence for cyclic electron flow around Photosystem II in Chlorella pyrenoidosa. Plant Physiol 81:310-312

Figueroa FL, Conde-Álvarez R, Gómez I (2003) Relations between electron transport rates determined by pulse amplitude modulated chlorophyll fluorescence and oxygen evolution in macroalgae under different light conditions. Photosynth Res 75:259-275

Flameling IA, Kromkamp J (1998) Light dependence of quantum yields for PSII charge separation and oxygen evolution in eukaryotic algae. Limnol Oceanogr 43: 284-297

> Flores-Moya A, Gómez I, Viñegla B, Altamirano M and others (1998) Effects of solar radiation on the endemic Mediterranean red alga Rissoella verruculosa: photosynthetic performance, pigment content and the activities of enzyme related to nutrient uptake. New Phytol 139: 673-683

Franklin LA, Badger MR (2001) A comparison of photosynthetic electron transport rates in macroalgae measured by pulse amplitude modulated chlorophyll fluorometry and mass spectrometry. J Phycol 37:756-767

Gévaert F, Créach A, Davoult D, Migné A and others (2003) Laminaria saccharina photosynthesis measured in situ: photoinhibition and xanthophyll cycle during a tidal cycle. Mar Ecol Prog Ser 247:43-50

Goto N, Miyazaki H, Nakamura N, Terai H, Ishida N, Mitamura O (2008) Relationships between electron transport rates determined by pulse amplitude modulated (PAM) chlorophyll fluorescence and photosynthetic rates by 
traditional and common methods in natural freshwater phytoplankton. Arch Hydrobiol 172:121-134

Häder DP, Figueroa FL (1997) Photoecophysiology of marine macroalgae. Photochem Photobiol 66:1-14

Hancke TB, Hancke K, Johnsen G, Sakshaug E (2008) Rate of $\mathrm{O}_{2}$ production derived from pulse-amplitudemodulated fluorescence: testing biooptical approaches against measured $\mathrm{O}_{2}$ production rate. J Phycol 44: 803-813

> Hanelt D, Huppertz K, Nultsch W (1993) Daily course of photosynthesis and photoinhibition in marine macroalgae investigated in the laboratory and field. Mar Ecol Prog Ser 97:31-37

Ihnken S, Eggert A, Beardall J (2010) Exposure times in rapid light curves affect photosynthetic parameters in algae. Aquat Bot 93:185-194

Jassby AD, Platt T (1976) Mathematical formulation of the relationship between photosynthesis and light for phytoplankton. Limnol Oceanogr 21:540-547

Kain JM (1971) The biology of Laminaria hyperborea. Oceanogr Mar Biol Rev Camb Philos Soc 17:101-161

Kain JM, Drew EA, Jupp BP (1976) Light and the ecology of Laminaria hyperborea. In: Evans GC, Bainbridge R, Rackham O (eds) Light as an ecological factor. Blackwell, Oxford, p 63-92

Laws EA, Archie JW (1981) Appropriate use of regression analysis in marine biology. Mar Biol 65:13-16

Littler MM (1979) The effects of bottle volume, thallus weight, oxygen saturation levels and water movement on apparent photosynthetic rates in marine algae. Aquat Bot $7: 21-34$

Longstaff BJ, Kildea T, Runcie JW, Chesshire A and others (2002) An in situ study of photosynthetic oxygen exchange and electron transport rate in the marine macroalga Ulva lactuca (Chlorophyta). Photosynth Res 74: 281-293

Lüning K (1979) Growth strategies of three Laminaria species (Phaeophyceae) inhabiting different depth zones in the sublittoral region of Helgoland (North Sea). Mar Ecol

Editorial responsibility: Christine Paetzold,

Oldendorf/Luhe, Germany
Prog Ser 1:195-207

Lüning K, Dring MJ (1979) Continuous underwater light measurement near Helgoland (North Sea) and its significance for characteristic light limits in the sublittoral region. Helgol Wiss Meeresunters 32:403-424

Mead R, Curnow RN (1983) Statistical methods in agriculture and experimental biology. Chapman \& Hall, London

> Morris EP, Kromkamp JC (2003) Influence of temperature on the relationship between oxygen- and fluorescencebased estimates of photosynthetic parameters in a marine benthic diatom (Cylindrotheca closterium). Eur J Phycol 38:133-142

Nielsen HD, Nielsen SL (2008) Evaluation of imaging and conventional PAM as a measure of photosynthesis in thin- and thick-leaved marine macroalgae. Aquat Biol 3: 121-131

> Nitschke U, Connan S, Stengel DB (2012) Chlorophyll a fluorescence responses of temperate Phaeophyceae under submersion and emersion regimes: a comparison of rapid and steady-state light curves. Photosynth Res 114:29-42

- Perkins RG, Mouget JL, Lefebvre S (2006) Light response curve methodology and possible implications in the application of chlorophyll fluorescence to benthic diatoms. Mar Biol 149:703-712

Prasil O, Kolber Z, Berry JA, Falkowsi PG (1996) Cyclic electron flow around Photosystem II in vivo. Photosynth Res 48:395-410

Ralph PJ, Gademann F (2005) Rapid light curves: a powerful tool to assess photosynthetic activity. Aquat Bot 82: 222-237

Sagert S, Forster RM, Feuerpfeil P, Schubert H (1997) Daily course of photosynthesis and photoinhibition in Chondrus crispus (Rhodophyta) from different shore levels. Eur J Phycol 32:363-371

Serôdio J, Viera S, Cruz S, Barroso F (2005) Short-term variability in the photosynthetic activity of microphytobenthos as detected by measuring light curves using variable fluorescence. Mar Biol 146:903-914

Submitted: October 30, 2012; Accepted: June 3, 2013 Proofs received from author(s): July 7, 2013 